\title{
Calcium-containing scaffolds induce bone regeneration by regulating mesenchymal stem cell differentiation and migration
}

\author{
Rubén Aquino-Martínez ${ }^{1,2}$, Alcira P. Angelo ${ }^{1}$ and Francesc Ventura Pujol ${ }^{1 *}$ (D)
}

\begin{abstract}
Background: Osteoinduction and subsequent bone formation rely on efficient mesenchymal stem cell (MSC) recruitment. It is also known that migration is induced by gradients of growth factors and cytokines. Degradation of $\mathrm{Ca}^{2+}$-containing biomaterials mimics the bone remodeling compartment producing a localized calcium-rich osteoinductive microenvironment. The aim of our study was to determine the effect of calcium sulfate $\left(\mathrm{CaSO}_{4}\right)$ on MSC migration. In addition, to evaluate the influence of $\mathrm{CaSO}_{4}$ on $\mathrm{MSC}$ differentiation and the potential molecular mechanisms involved.

Methods: A circular calvarial bone defect ( $5 \mathrm{~mm}$ diameter) was created in the parietal bone of $35 \mathrm{Balb}-\mathrm{C}$ mice. We prepared and implanted a cell-free agarose/gelatin scaffold alone or in combination with different $\mathrm{CaSO}_{4}$ concentrations into the bone defects. After 7 weeks, we determined the new bone regenerated by micro-CT and histological analysis. In vitro, we evaluated the $\mathrm{CaSO}_{4}$ effects on MSC migration by both wound healing and agarose spot assays. Osteoblastic gene expression after $\mathrm{BMP}^{-2}$ and $\mathrm{CaSO}_{4}$ treatment was also evaluated by qPCR.

Results: $\mathrm{CaSO}_{4}$ increased MSC migration and bone formation in a concentration-dependent manner. Micro-CT analysis showed that the addition of $\mathrm{CaSO}_{4}$ significantly enhanced bone regeneration compared to the scaffold alone. The histological evaluation confirmed an increased number of endogenous cells recruited into the cell-free $\mathrm{CaSO}_{4}$-containing scaffolds. Furthermore, MSC migration in vitro and active AKT levels were attenuated when $\mathrm{CaSO}_{4}$ and BMP-2 were in combination. Addition of LY294002 and Wortmannin abrogated the $\mathrm{CaSO}_{4}$ effects on MSC migration.

Conclusions: Specific $\mathrm{CaSO}_{4}$ concentrations induce bone regeneration of calvarial defects in part by acting on the host's undifferentiated MSCs and promoting their migration. Progenitor cell recruitment is followed by a gradual increment in osteoblast gene expression. Moreover, $\mathrm{CaSO}_{4}$ regulates BMP-2-induced MSC migration by differentially activating the PI3K/AKT pathway. Altogether, these results suggest that $\mathrm{CaSO}_{4}$ scaffolds could have potential applications for bone regeneration.
\end{abstract}

Keywords: Osteoinduction, Mesenchymal stem cells, Migration, Bone grafts, Calcium sulfate, Bone morphogenetic protein, Craniofacial, Bone regeneration, Bone remodeling

\footnotetext{
* Correspondence: fventura@ub.edu

${ }^{1}$ Departament de Ciències Fisiològiques, Universitat de Barcelona, IDIBELL,

L'Hospitalet de Llobregat, Barcelona, Spain

Full list of author information is available at the end of the article
} 


\section{Background}

Osteoinduction is initiated by guided attraction of the host's mesenchymal stem cells (MSCs) from adjacent tissues in response to chemotactic cues released from the bone graft or the implanted biomaterial. Bone induction is a stepwise cascade of cellular and biochemical events and has been divided into different phases. The initial phase involves MSC chemotaxis, followed by a few rounds of proliferation and differentiation [1-3]. The importance of osteoinduction for bone healing and osteointegration of dental implants is that the majority of newly formed bone depends on the undifferentiated cells that are induced to become preosteoblasts [4].

During remodeling osteoclasts release a myriad of signaling molecules from the bone matrix. These soluble signals diffuse and create an osteoinductive microenvironment that promotes the osteoprogenitor cell recruitment into the resorbed lacunae. Under physiological conditions, osteoprogenitor cell motility relies not only on a single growth factor but on a chemoattractant gradient formed by multiple biochemical signals. Several studies have demonstrated that extracellular calcium (the main component of the mineralized bone), TGF- $\beta$, BMP-2, BMP-4, PDGF, and other growth factors have a promigratory effect over the MSCs [5-9].

$\mathrm{CaSO}_{4}$ is likely the simplest alternative as a synthetic bone graft material and has been used for more than 100 years $[10,11] . \mathrm{CaSO}_{4}$ has been used in clinical implant dentistry [12], craniofacial surgery [13], correction of alveolar cleft in children [14], periradicular endodontic surgery [15], and orthopedic surgery [16, 17], producing effective and consistent results. $\mathrm{CaSO}_{4}$ and calcium phosphate compounds mimic the mineral phase of bone. They induce a biological response similar to that generated during bone remodeling, creating a calcium-rich environment in the area of implantation [18-20]. Several cellular in-vivo mechanisms have been proposed to explain the beneficial effects of $\mathrm{CaSO}_{4}$ on bone regeneration. Walsh et al. [21] suggested that the decreased $\mathrm{pH}$ and the local acidity produced during $\mathrm{CaSO}_{4}$ resorption cause a demineralization of the adjacent bone and release matrix-bound BMPs. In addition, increased angiogenesis in the sites treated with $\mathrm{CaSO}_{4}$ could account for the good results reported [11]. Currently, the cellular and molecular mechanisms involved in the osteogenic effects produced by $\mathrm{CaSO}_{4}$ remain poorly understood.

To date, over 20 BMP family members have been isolated and characterized. BMP-2, BMP-4, and BMP- 6 are the most readily detectable BMPs on bone tissue [22]. The BMP/Smad pathway is one of the most prominent signaling pathways promoting osteogenic differentiation. However, binding of BMPs also triggers the activation of Smad-independent pathways including PI3K/AKT or p38 [23-25]. BMP target genes include a growing number of osteoblast determining transcription factors such as Runx2, Osterix, and $D l \times 3 / 5$ which are essential for osteoblast differentiation [26, 27].

In our previous study, we presented a critical-size calvarial bone defect model in mice using an agarose/ gelatin $/ \mathrm{CaSO}_{4}$ scaffold. We demonstrated that ex-vivo pretreatment of MSCs with very low concentrations of BMP-2 (2 nM) and Wnt3a (50 ng/ml) cooperatively increases bone regeneration in vivo [28]. Notably, an abundant endogenous cellular invasion was observed histologically when an agarose/gelatin $/ \mathrm{CaSO}_{4}$ scaffold without the addition of cells or growth factors was implanted into the bone defects. In the present study we soaked the gelatin sponges in $\mathrm{CaSO}_{4}$ solutions. Soaking has also been used as a conventional method for loading BMP-2 [29, 30]. Therefore, the aim of this study was to determine the MSC migratory response to $\mathrm{CaSO}_{4}$ in vitro and in vivo using a critical-size calvarial bone defect model in mice. In addition, to evaluate the effects of $\mathrm{CaSO}_{4}$ on MSC differentiation and the potential molecular mechanism involved in such effects.

\section{Methods \\ Mesenchymal stem cell isolation and culture}

For the in-vitro experiments, bone marrow MSCs were obtained from male mice as described previously [28, 31]. Briefly, MSCs were isolated from BALB/C mice 6-8 weeks old. The tibia and femur were collected from euthanized mice and muscle was removed. The methaphyses were cut and the bone marrow flushed with complete media and filtered using a 70- $\mu \mathrm{m}$ strainer (BD Falcon) before seeding. The cells were cultured using DMEM supplemented with $10 \%$ fetal bovine serum (FBS), penicillin/ streptomycin, $1 \mathrm{mM}$ pyruvate, and $2 \mathrm{mM}$ glutamine. Nonadherent cells were removed during the first days, and when the attached cells reach $80 \%$ confluence they were trypsinized for 3 minutes at room temperature. The lifted cells were expanded for a maximum of six to eight passages and used in subsequent experiments.

\section{Two-dimensional cell culture preparation}

Two-dimensional cultures were performed in wells coated with $0.1 \%$ gelatin solution dissolved in PBS (control). A $\mathrm{CaSO}_{4}$ stock solution in DMEM was filtered using a 70- $\mu \mathrm{m}$ strainer. For those conditions containing $\mathrm{CaSO}_{4}$, different concentrations were mixed with the gelatin solution. Treated plates were air-dried overnight in the cell culture hood and stored at room temperature until needed.

\section{Cell migration assays \\ Wound healing assay}

MSCs $\left(5 \times 10^{4}\right.$ cells) were grown to confluence using the gelatin (control) or gelatin/ $\mathrm{CaSO}_{4}$-coated 24-well plates (from 3 to $15 \mathrm{mM}$ ). Twenty-four hours before starting 
the assay, standard media were replaced with media containing 1\% FBS. The confluent cells were then "wounded" with a plastic tip and washed to remove detached cells. The wound was allowed to close for 24 hours. To confirm the specificity of calcium on MSC migration, EDTA was used at the same concentrations as $\mathrm{CaSO}_{4}$. The concentrations used for BMP-2 were 0.2, 2, and $10 \mathrm{nM}$. For PI3K inhibition, LY294002 $(10 \mu \mathrm{M})$ and Wortmannin $(500 \mathrm{nM})$ were used. The wound was photographed with a Leica DM IRB2 microscope linked to an Olympus DP50 camera. The rate of cell migration was measured as the percentage of invaded area with respect to the initial wound area [32].

\section{Agarose spot assay}

Agarose spot assay was performed following the protocols described previously [33-35]. Low-melting agarose (Sigma-Aldrich) was diluted into PBS to make a $1 \%$ agarose solution and then autoclaved. To prepare the agarose spots, $100 \mu \mathrm{l}$ of melted $1 \%$ agarose solution was added into a 1.5-ml Eppendorf tube containing $100 \mu \mathrm{l}$ of PBS or $6 \mathrm{mM} \mathrm{CaSO}_{4}$ solution (to obtain a final concentration of $0.5 \%$ and $3 \mathrm{mM}$ respectively). Two separated $1-\mu \mathrm{l}$ spots, one spot containing $\mathrm{CaSO}_{4}$ and one containing only PBS, were pipetted onto $35-\mathrm{mm}$ dishes. The dish was cooled for 5 minutes at $4{ }^{\circ} \mathrm{C}$ to allow the spot to solidify. Meanwhile, MSCs were tripsinized and resuspended in 1\% FBS media. After centrifugation $(1500 \mathrm{rpm})$ the pellet was resuspended and $5 \times 10^{5}$ cells were pipetted into the plates containing the spots and incubated overnight. Cells were fixed 24 hours later with $4 \%$ paraformaldehyde, analyzed by microscopy, and photographed. The degree of cells invading the agarose spot was analyzed by counting the number of cells and the invaded surface measured as the percentage of invaded area with respect to the initial area of the spot using ImageJ software.

\section{Cell proliferation assays}

MSC proliferation was evaluated using 7-AAD and BrdU labeling (BD, CA, USA), following the manufacturer's protocol. Briefly, $5 \times 10^{4}$ cells were seeded and incubated at $37^{\circ} \mathrm{C}$ for 24 hours. Then, BrdU $(10 \mu \mathrm{M})$ was added to the medium for 45 minutes. The cells were harvested and analyzed by flow cytometry.

\section{In-vivo calvarial bone defect model}

A total of $35 \mathrm{BALB} / \mathrm{c}$ male mice 10 weeks old were anesthetized by isoflurane inhalation (Abbott) and an intraperitoneal injection of buprenorphine $(0.05 \mathrm{mg} / \mathrm{kg})$ was administered for intraoperative analgesia. The procedure was performed as described previously [28]. Briefly, after shaving the incision area a longitudinal incision was made and the periosteum was elevated to expose the cranium. A circular critical-size defect was produced in the parietal bone using a 5-mm-diameter trephine and a dental implant motor. Importantly, minimal irrigation was used to heat-damage the host bone on the edges to minimize spontaneous healing [36]. The bone disk was removed carefully and the bone defect was covered with a randomly selected scaffold according to the experimental group (see Table 1). The skin was sutured and the animals were monitored daily during recovery. All animal procedures were performed in accordance with the protocols approved by the Ethics Committee for Animal Experimentation of the University of Barcelona and by the Generalitat of Catalunya.

\section{Cell-free scaffold preparation for the in-vivo experiment}

Low-melting agarose (Sigma-Aldrich), gelatin sponges (Gelita, B. Braun), and biphasic $\mathrm{CaSO}_{4}$ were employed to prepare a cell-free scaffold. Under sterile conditions, the gelatin sponges were cut into pieces $7 \mathrm{~mm} \times 7 \mathrm{~mm}$ and $5 \mathrm{~mm}$ thick, and soaked in serum-free media alone or containing $\mathrm{CaSO}_{4}$ or BMP-2 as presented in Table 1. One dish $(60 \mathrm{~mm})$ containing $3 \mathrm{ml}$ of each solution was used to soak the prepared sponges and keep them in the incubator for 24 hours. Before the in-vivo experiment, $3 \mathrm{ml}$ of melted agarose 1\% was added to the dish containing both the soaked sponges and the corresponding solution. The dish was cooled for 5 minutes at $4{ }^{\circ} \mathrm{C}$ to allow solidification of the construct. Each piece containing the condition of study was trimmed using a scalpel and implanted carefully into the created bone defect.

\section{Bone regeneration analyses}

Seven weeks after the implantation the animals were euthanized by $\mathrm{CO}_{2}$ inhalation, and the heads fixed in $4 \%$ paraformaldehyde for 24 hours and stored in PBS/azide at $4{ }^{\circ} \mathrm{C}$ until scanning. Scanning was performed by a Skyscan 1076 high resolution (Skyscan, Belgium). The exposure parameters were $49 \mathrm{kV}, 200 \mathrm{~mA}, 500 \mathrm{~ms}$, 1-mm aluminum filter, and $180^{\circ}$ rotation. Data reconstruction was performed using NRecon and threedimensional models using CTAn software. For the histological analysis, the dissected calvariae were decalcified with Decalcifier II (Leica Biosystems) for 2-3 days. After decalcification, the samples were dehydrated, embedded in paraffin, and sectioned.

Table 1 Experimental groups used for in-vivo calvarial defects

\begin{tabular}{ll}
\hline Group & Treatment \\
\hline 1. Control & Serum-free media (SFM) \\
2. Bone morphogenetic protein 2 & SFM $+2 \mathrm{nM}$ \\
3. Calcium sulfate & $\mathrm{SFM}+10 \mathrm{mM}$ \\
4. Calcium sulfate & $\mathrm{SFM}+20 \mathrm{mM}$ \\
5. Calcium sulfate & $\mathrm{SFM}+50 \mathrm{mM}$ \\
\hline
\end{tabular}


Sections of $6 \mu \mathrm{m}$ were stained with hematoxylin and eosin (HE). We quantified the cell number in the histological sections using ImageJ software. Immunohistochemistry was performed using a primary antibody against Osterix (Ab22552) at 1:200 dilution overnight. The slides were incubated with $\mathrm{DAB}$ and counterstained with hematoxylin.

\section{Quantitative RT-PCR analysis}

After 24 hours, MSCs cultured on a coated 12-well plate were lysed using Trisure (Bioline), following the manufacturer's instructions. RNA quantification was performed by spectrophotometric analysis (Nanodrop ND 1000; Thermo Scientific). Purified RNA $(2 \mu \mathrm{g})$ was reverse-transcribed using a High-Capacity Retrotranscription Kit (Applied Biosystems), and 50 ng of cDNA per reaction was used in each qRT-PCR with two replicates per sample. The gene expression was analyzed using Taqman probes (Applied Biosystems)-Osterix (Sp7) (Mm00504574_m1), Alpl (Mm00475834_m1), and Osteocalcin/Bglap (Mm00649782_g1) -and normalized to Gapdh (Mm99999915_g1). Mean CT values were used for $2^{-\Delta \Delta C T}$ quantification.

\section{Western blot assay}

Cells were washed twice with cold PBS and lysed by adding $75 \mu \mathrm{l}$ of buffer containing PBS, $100 \mathrm{mM}$ PMSF, $1 \mathrm{mM}$ sodium orthovanadate, $10 \mathrm{mM} \beta$-glycerophosphate, $1 \mu \mathrm{g} / \mathrm{ml}$ leupeptin, $1 \%$ Triton X-100, $10 \mathrm{mM} \mathrm{NaF}$, and $1 \mu \mathrm{g} / \mathrm{ml}$ pepstatin, for 1 hour at $4{ }^{\circ} \mathrm{C}$. The lysates $(30 \mu \mathrm{g}$ of protein) were subjected to SDS-PAGE and transferred to membranes, which were incubated with the following primary antibodies: pAKT (Ser 473) (Cell Signaling) and $\alpha$-Tubulin (T6199) (Sigma). Horseradish peroxidase-conjugated secondary antibodies were utilized, followed by EZ-ECL reagent incubation (Biological Industries). A chemoluminescent image was captured by a Fujifilm LAS 3000 device.

\section{Statistical analyses}

Data were obtained from at least three independent experiments and presented as mean \pm SEM. The analyses were performed using Student's $t$ test with GraphPad Prism 5 software. The differences were considered significant at $p<0.05, p<0.01$, and $p<0.001$.

\section{Results}

\section{$\mathrm{CaSO}_{4}$ induces $\mathrm{MSC}$ migration in vitro}

In order to evaluate the MSC migration response, the cells were exposed to different $\mathrm{CaSO}_{4}$ concentrations and allowed to migrate for 24 hours. Using a wound healing assay we observed a $\mathrm{CaSO}_{4}$ concentrationdependent effect on MSC migration. A significantly higher response was observed at 3-5 $\mathrm{mM}$ concentrations compared to the control (Fig. 1a, b). However, there was a gradually decreasing response in those cells exposed to doses higher than $10 \mathrm{mM}$. To confirm the $\mathrm{CaSO}_{4}$ influence on MSC migration, an agarose spot assay was performed. As shown in Fig. 1c, d, a higher number of migrated cells and percentage of invaded surface was observed in the presence of $\mathrm{CaSO}_{4} 3 \mathrm{mM}$ compared to the control (PBS). In addition, to test the specificity of calcium on the migration of MSCs, EDTA was added. As shown in Fig. 1e, f, the $\mathrm{CaSO}_{4}$ effect was completely abolished when calcium was chelated by EDTA. We also tested the proliferation of the MSCs cultured for 24 hours. The results showed that control and $\mathrm{CaSO}_{4}$-treated cells had no significant differences in their proliferative rate after the BrdU incorporation and flow cytometry analysis (Additional file 1: Figure S1). These results demonstrate that in-vitro $\mathrm{CaSO}_{4}$ induces a promigratory effect on MSCs in a concentrationdependent manner. An optimal range between 3 and $5 \mathrm{mM}$ promotes migration.

\section{$\mathrm{CaSO}_{4}$ increases bone regeneration in vivo by recruiting the host's osteoprogenitor cells}

We implanted cell-free agarose/gelatin scaffolds, with or without $\mathrm{CaSO}_{4}$, into the critical-size calvarial bone defects. After 7 weeks, micro-CT morphometric analysis (BV/TV) showed a lower amount of regenerated bone in the control group $(15.06 \% \pm 5.15)$. BMP-2 $(2 \mathrm{nM})$ increased the regeneration ability $(23.06 \% \pm 2.9)$. Bone formation was significantly higher $(37.48 \% \pm 7.02)$ in those conditions soaked in $20 \mathrm{mM}$ solution $(p<0.05)$. However, these positive effects of $\mathrm{CaSO}_{4}$ were reduced in the $50 \mathrm{mM} \mathrm{CaSO}{ }_{4}$-soaked group $(24.5 \% \pm 2.99)$ (Fig. 2). Histological analysis from HE preparations showed increased host's cell migration into the implanted calciumcontaining scaffolds, as shown in Fig. 3a, b. Consistent with the micro-CT and histological analyses, $\mathrm{CaSO}_{4}$ groups improved substantially the host's osteoprogenitor cell recruitment (Osx positive) (Fig. 3c). Therefore, these results suggest that bone regeneration of the calvarial defect was correlated to the ability of $\mathrm{CaSO}_{4}$ to recruit the host's osteoprogenitor cells into the implanted scaffolds.

\section{$\mathrm{CaSO}_{4}$ attenuates BMP-2-mediated MSC migration and AKT activation}

During bone resorption, ions, cytokines, and growth factors, including BMPs, are released from the bone matrix, promoting osteoprogenitor cell recruitment $[37,38]$. We treated MSCs with BMP-2 concentrations $(0.2,2$, and $10 \mathrm{nM}$ ) that have been shown to induce Osx expression and osteoblast commitment [26, 27] A maximal migration response was observed in those MSCs exposed to $2 \mathrm{nM}$ (Additional file 2: Figure S2A). Interestingly, higher BMP-2 concentrations (10 nM) decreased such an effect on migration. Our results suggest that higher 


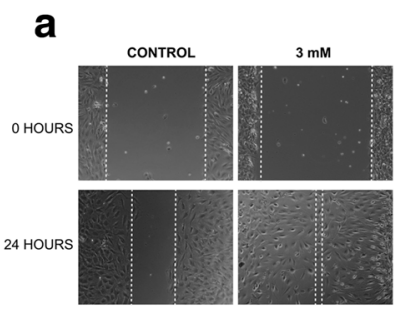

C

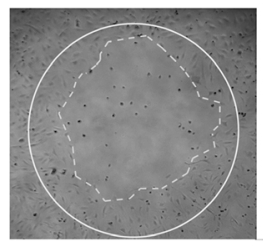

CONTROL
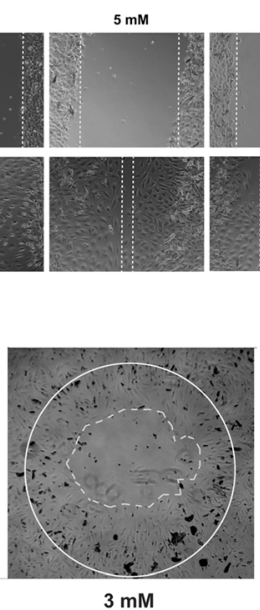

e

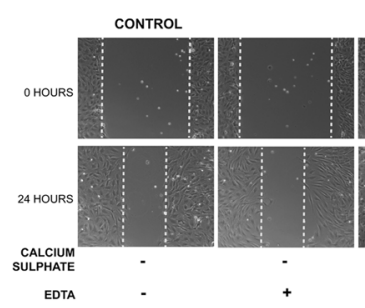

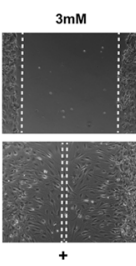

$+$

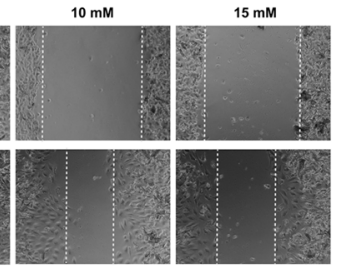

d

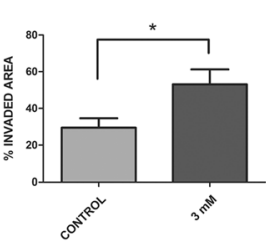

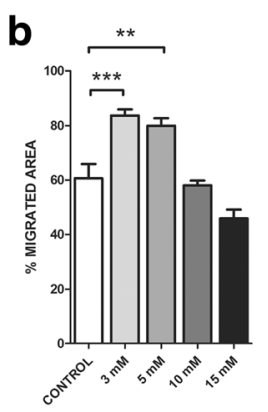
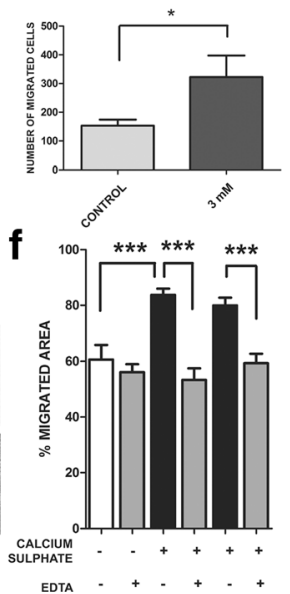

Fig. $1 \mathrm{CaSO}_{4}$ promotes MSC migration in a concentration-dependent manner. $\mathbf{a}$, $\mathbf{b}$ Wound healing or scratch assay used to measure MSC migration response to different $\mathrm{CaSO}_{4}$ concentrations (3-15 mM) after 24 hours. Results shown as average of four different experiments with six replicates for each condition. A representative image displayed for each condition. c, d Agarose spot assay used to confirm the effect of CaSO 4 (3 mM) on $\mathrm{MSC}$ migration compared to control (PBS). Results presented as percentage of invaded area and number of migrated cells. Six replicates were performed. e, $\mathbf{f} \mathrm{CaSO}_{4}(3-5 \mathrm{mM})$ migration effect was completely abolished when calcium was chelated by the addition of equal EDTA concentrations. Data presented as mean \pm SEM. Differences considered significant at ${ }^{*} p<0.05,{ }^{* *} p<0.01$, and ${ }^{* * *} p<0.001$. EDTA ethylenediaminetetraacetic acid
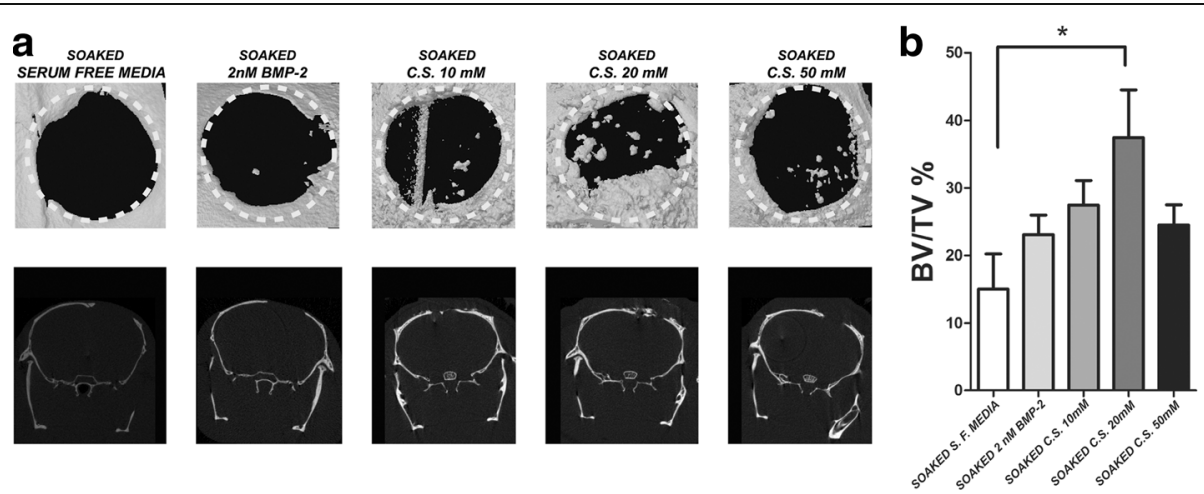

Fig. 2 Bone regeneration quantification of critical-size calvarial bone defects by micro-CT analysis. a Regeneration of critical-size calvarial bone defects ( $5 \mathrm{~mm}$ diameter) quantified after 7 weeks of cell-free scaffold implantation. Representative coronal and sagittal images of the control group (soaked in serum-free media), 2 nM BMP-2, $\mathrm{CaSO}_{4}$ (C.S.) $10 \mathrm{mM}$, C.S. $20 \mathrm{mM}$, and C.S. $50 \mathrm{mM}$. b Quantitative analysis of new bone formation by bone volume/tissue volume (BV/TV). Quantitative data presented as mean \pm SEM. Differences considered significant at ${ }^{*} p<0.05$. BMP bone morphogenetic protein, S. F. serum free 

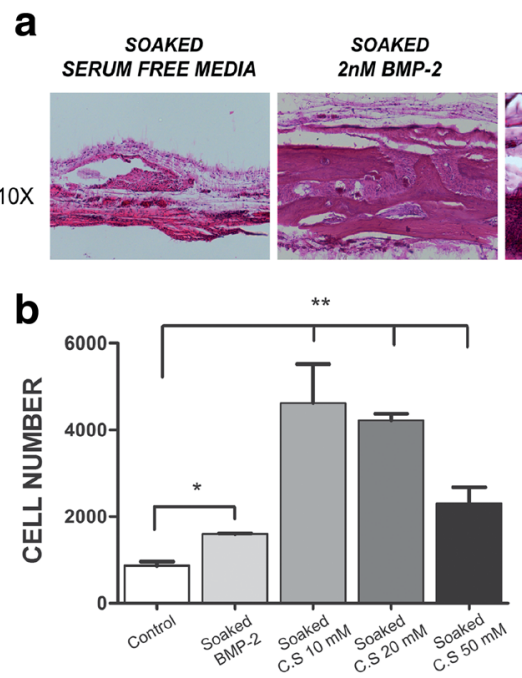
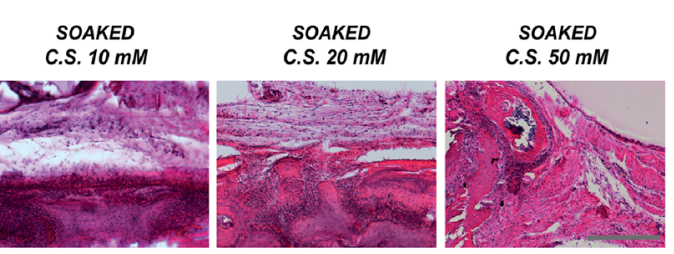

C

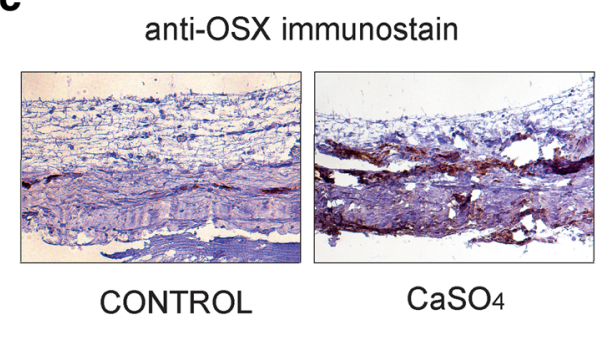

Fig. $3 \mathrm{CaSO}_{4}$ increases bone regeneration in vivo by recruiting the host's cells into the bone defect. a HE staining shows host's cells recruited into the cell-free implanted scaffold. Representative images of the control group (soaked in serum-free media), 2 nM BMP-2, CaSO 4 (C.S.) 10 mM, C.S. $20 \mathrm{mM}$, and C.S. $50 \mathrm{mM}$ taken from the center of the defect. 10x, scale bar $=400 \mu \mathrm{m}$. $\mathbf{b}$ Recruited cells into the different scaffolds quantified as described in Methods. c Osteoprogenitor cells expressing Osterix (OSX) identified in a representative implanted control and calcium-containing scaffold by immunohistochemistry. Differences considered significant at ${ }^{*} p<0.05,{ }^{* *} p<0.01$. BMP bone morphogenetic protein

osteoblastic commitment (assessed by Osterix expression) could correlate with a decrease in the ability of MSCs to migrate (Additional file 2: Figure S2B). Therefore, we also assessed the $\mathrm{CaSO}_{4}$ effects on BMP-2-induced migration activity. MSCs were treated with $\mathrm{CaSO}_{4} 3 \mathrm{mM}$ and/or BMP-2 2 nM for 24 hours. Consistent with our results, $\mathrm{CaSO}_{4}$ and BMP-2 alone promoted a significantly higher migratory effect compared to untreated cells. The MSC migration response to $\mathrm{CaSO}_{4}$ or BMP-2 was closely similar when they acted independently. However, when both signals were added together a lower migration was observed (Fig. 4a, b).

To determine the potential molecular mechanism involved in the ability of $\mathrm{CaSO}_{4}$ and BMP-2 to induce migration, we evaluated the phosphorylation of AKT as a target downstream of PI3K. As shown in Fig. 4d, only BMP-2 increased the activation of AKT. By contrast, when $\mathrm{CaSO}_{4}$ is combined with BMP-2 a consistent attenuation in the phosphorylation of AKT is observed at 24 hours. In addition, we assessed the effects of two different PI3K inhibitors, L294002 and Wortmannin, on $\mathrm{CaSO}_{4}$-induced migration. As shown in Fig. 4c, both inhibitors abrogate the induced migration of MSCs. Interestingly, there was a statistically higher inhibitory effect in those conditions treated with Wortmannin that in those exposed to LY2940002. Taken together, $\mathrm{CaSO}_{4}$ and BMP-2 induce MSC migration by distinct mechanisms and the former could attenuate the ability of the latter to increase migration.

\section{$\mathrm{CaSO}_{4}$ effects on osteogenic gene expression}

Enhanced osteogenic gene expression and osteoblast differentiation in MSCs cultured on calcium-based biomaterials or in the presence of additional calcium concentrations in the culture media have been reported [39]. We determined the effects of different $\mathrm{CaSO}_{4}$ concentrations on MSC differentiation after 1, 4, and 10 days. As shown in Fig. 5, downregulation on day 1 was followed by a gradual increment of Osterix, Alpl, and Osteocalcin mRNA expression from day 4 to day 10 . These results suggest that $\mathrm{CaSO}_{4}$ produces a dual effect on MSC differentiation into osteoblasts. Initially (1-4 days), there is a transiently attenuating effect on differentiation followed by a progressive upregulation of osteogenic genes, such as Osterix, Alpl, or Osteocalcin.

\section{Discussion}

Following implantation of demineralized bone matrix (DBM), MSCs undergo directed migration in response to matrix chemoattractants [40]. Indeed, the induction of bone formation requires three key components: an osteoinductive soluble signal, an insoluble substratum, and responding host's cells $[41,42]$. We hypothesized that $\mathrm{CaSO}_{4}$ could act as a promigratory signal and would induce the recruitment of such endogenous cells. We checked this hypothesis using a gelatin sponge as a substratum to provide initial attachment to the osteoprogenitor cells and agarose to both provide a sustained $\mathrm{Ca}^{2+}$ release and serve as a binding agent. Our findings strongly 


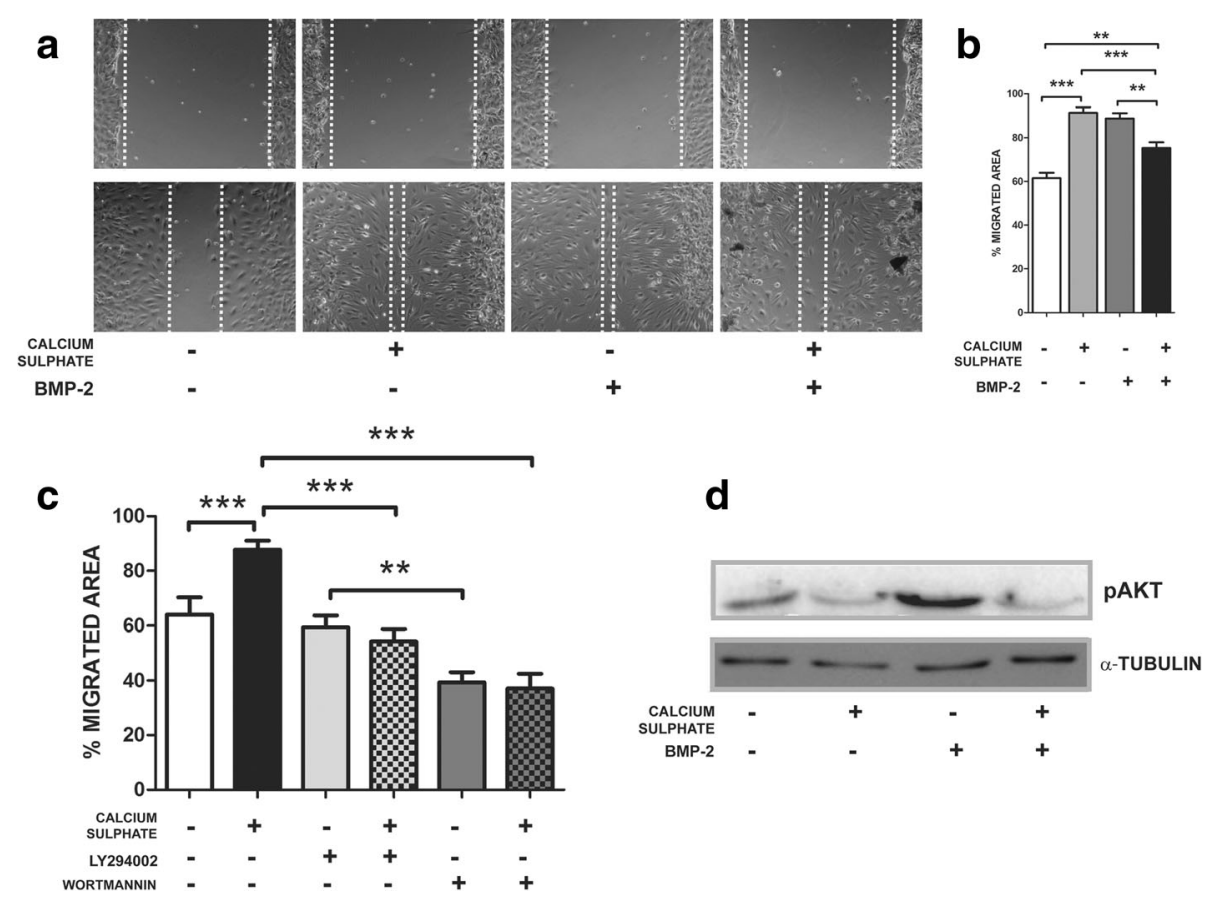

Fig. $4 \mathrm{CaSO}_{4}$ modulates migration and AKT activation induced by BMP-2. a, b Wound healing assay evaluating the effects of $\mathrm{CaSO}_{4} 3 \mathrm{mM}$ and BMP-2 2nM alone or in combination on MSC migration after 24 hours of culture. Results shown as average of three different experiments with six replicates for each condition. A representative image displayed for each condition. Note that CaSO4 and BMP-2 produced a similar effect on MCS migration. c Wound healing assay to assess effects of LY294002 or Wortmannin (PI3K/AKT inhibitors at $10 \mu \mathrm{M}$ and $500 \mathrm{nM}$ respectively) on MSC chemotaxis. Migration was abrogated when $\mathrm{MSCs}$ were treated simultaneously with $\mathrm{CaSO}_{4}$ and such inhibitors. d MSCs were cultured with $\mathrm{CaSO}_{4}$ $3 \mathrm{mM}$ and BMP-2 2nM alone or in combination for 24 hours, and extracts analyzed by western blot assay and quantified relative to a-Tubulin. Differences considered significant at ${ }^{* *} p<0.01$, and ${ }^{* *} p<0.001$. BMP bone morphogenetic protein

suggest that $\mathrm{CaSO}_{4}$ has the ability to recruit osteoprogenitor cells in vitro and in vivo.

Our results showed that there is an optimal range of $\mathrm{CaSO}_{4}$ concentration to promote MSC migration. In our model this range is between 3 and $5 \mathrm{mM}$ in vitro, whereas in vivo a threshold for an osteoinductive effect was determined in those scaffolds soaked in a solution of $\mathrm{CaSO}_{4}$ $20 \mathrm{mM}$. Yamaguchi et al. [5] found that exposure of MC3T3-E1 cells to high $\mathrm{CaCl}_{2}$ (up to $4.8 \mathrm{mM}$ ) in vitro resulted in dose-dependent chemotaxis stimulation. In addition, we also observed that the addition of higher $\mathrm{CaSO}_{4}$ concentrations disturbed MSC migration in vitro and bone regeneration in vivo according to the micro-CT and histological analysis. It has been shown that extracellular fluid at sites of injury, infection, or inflammation contains high concentrations of calcium [43]. Interestingly, rapid resorption of $\mathrm{CaSO}_{4}$ results in a $\mathrm{Ca}^{2+}$-rich fluid that could modulate inflammation and apoptosis [44, 45].

Furthermore, we evaluated the effect of $\mathrm{CaSO}_{4}$ on MSC differentiation. Osteoblast differentiation is regulated by
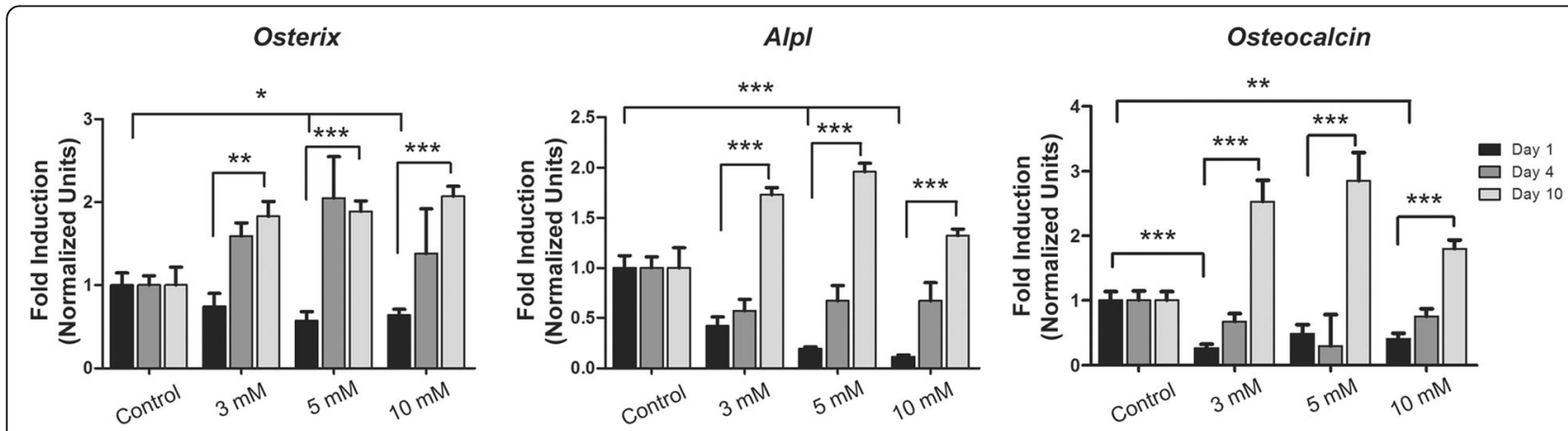

Fig. $5 \mathrm{CaSO}_{4}$ effects on Osterix, Alpl, and Osteocalcin gene expression. MSCs were cultured with different $\mathrm{CaSO}_{4}$ concentrations (3-10 mM) and Osterix, Alpl, and Osteocalcin expression evaluated after 1, 4, and 10 days. Three different experiments were performed. Data presented as mean \pm SEM. Differences considered significant at ${ }^{*} p<0.05,{ }^{* *} p<0.01$, and ${ }^{* * *} p<0.001$ 
the sequential expression of several osteogenic marker genes $[46,47]$. In this study, $\mathrm{CaSO}_{4}$ lowered the expression of Osterix at 24 hours and Alpl or Osteocalcin up to 4 days but increased all of them after 10 days in culture. In agreement with our results, Lazary et al. [48] have shown that expression of Osteocalcin (Bglap), Bone Sialoprotein (Ibsp), and Col1a1 was decreased when MC3T3-E1 cells were cultured on $\mathrm{CaSO}_{4}$ discs or with medium supplemented with $\mathrm{CaCl}_{2} 25 \mathrm{mM}$. The Smad pathway transduces signals from BMP receptors and leads to transcriptional induction of key osteogenic transcription factors such as Runx2 and Osterix. It has been shown that other growth factors, such as TGF- $\beta$, HGF, EGF, FGF, or IGF, also induce a chemotactic response on MSCs. However, these growth factors individually also induce an antagonistic effect on BMP-induced osteoblast differentiation by inhibiting the nuclear accumulation of Smads [49-51].

In addition, it has been reported that genes downstream of G-protein coupled receptor (GPCR) signaling pathways may be the earliest response to calcium-based ceramics [52]. Indeed, calcium sensing receptor (CaSR), a receptor belonging to the GPCR family, modulates the chemotactic response of MSCs in response to extracellular calcium $[5,6,53]$. It has been reported that $\mathrm{CaSO}_{4}$ induces a significant increment in Smad3 and Smad6 expression [48]. Smad3 and Smad6 have an inhibitory effect on BMP signaling during osteoblast differentiation by targeting the BMP-responsive Smad1/5/8 complex $[49,54]$. It has been demonstrated that high extracellular calcium decreased the levels of phosphorylated SMAD1, ERK $1 / 2$, and p38 and that $\mathrm{Ca}^{2+}$ could bind BMP-2 extracellularly $[55,56]$. In contrast, low concentrations of extracellular calcium (0.18 mM) enhanced BMP-2induced osteogenic differentiation [55]. Interestingly, $\mathrm{Sr}^{2+}$ produces a similar inhibitory effect on BMP-2 osteogenic capacity via the canonical Smad pathway [57]. Altogether, these results suggest that $\mathrm{CaSO}_{4}$ transiently attenuates BMP-2 signaling, antagonizing the canonical Smad1/5/8, with subsequent Osterix downregulation.

In our study we observed a differential activation of AKT levels by $\mathrm{CaSO}_{4}$ and BMP-2. A lower AKT phosphorylation was observed in $\mathrm{CaSO}_{4}$-treated conditions. Moreover, LY294004 and Wortmannin treatment abolished the migration induced by $\mathrm{CaSO}_{4}$, supporting the evidence that $\mathrm{Ca}^{2+}$-induced migration could be mediated by AKT. In agreement with our results, it has been reported that extracellular calcium produces early AKT activation with maximal effect between 5 and 60 minutes [58-60]. Class I PI3Ks are divided into class IA (PI3K $\alpha$, PI3K $\beta$, and PI3K $\delta$ ) and class IB (PI3K $\gamma)$. It has been demonstrated that BMP-2 induces AKT phosphorylation through the specific activation of the PI3K $\alpha$ isoform [32]. In contrast, PI3K $\gamma$ is almost exclusively activated by GPCRs [61, 62]. Several studies have reported that GPCR activation inhibits PI3K signaling [63]. Of note, class IA isoform $\mathrm{p} 110 \alpha$ (activated by BMP-2) might be inhibited by the GTP-bound G $\beta \gamma$ subunit which is downstream of GPCRs [63-65]. Altogether, our results suggest a novel mechanism by which $\mathrm{CaSO}_{4}$ modulates MSC migration by attenuating BMP-2 activation of AKT.

Migration of undifferentiated MSCs dramatically decreases during further steps of osteogenic differentiation [66] and also leads to lower response to chemotactic factors [9]. Therefore, an initial modulation of osteoblast differentiation could promote progenitor cell recruitment. There are at least two aspects in our study relevant to understanding some of the biological mechanisms whereby $\mathrm{Ca}^{2+}$ promotes bone regeneration. First, $\mathrm{CaSO}_{4}$ promotes MSC migration in a concentration-dependent fashion and modulates BMP-2-induced migration. Second, $\mathrm{CaSO}_{4}$ exerts a biphasic effect on MSC differentiation. An initial transient attenuation of BMP-2 promoted differentiation which is followed by a progressive increment in the expression of osteoblastic genes, such as Osterix, Alpl, or Osteocalcin. Therefore, $\mathrm{Ca}^{2+}$ may act on undifferentiated MSCs promoting migration by modulating PI3K/AKT activation and simultaneously delaying a mature osteoblast phenotype which is correlated with decreased motility.

\section{Conclusion}

Calcium sulfate $\left(\mathrm{CaSO}_{4}\right)$, as source of $\mathrm{Ca}^{2+}$, promotes invitro MSC migration and bone regeneration in vivo by recruiting the host's osteoprogenitors into the implanted cell-free scaffold. This response might be mediated by both a transient attenuation of BMP-induced Osterix expression and increasing MSC recruitment. To our knowledge, this is one of the first studies covering the relationship between MSC migration and differentiation induced by $\mathrm{CaSO}_{4}$. Our results could be relevant to understand the mechanisms of osteoinduction and implement potential clinical applications of $\mathrm{CaSO}_{4}$ to regenerate craniofacial bone defects.

\section{Additional files}

Additional file 1: Figure S1. Effects of $\mathrm{CaSO} 4$ on proliferation of BM-MSCS. (TIF $5165 \mathrm{~kb}$ )

Additional file 2: Figure S2. Dose-response effects of $\mathrm{CaSO} 4$ on migration and Osx expression. (TIF 3900 kb)

\footnotetext{
Abbreviations

Alpl: Alkaline phosphatase; Bglap: Osteocalcin; BMP-2: Bone morphogenetic protein 2; $\mathrm{CaCl}_{2}$ : Calcium chloride; CaSR: Calcium sensing receptor;

Col1a1: Collagen type 1; DBM: Demineralized bone matrix;

EDTA: Ethylenediaminetetraacetic acid; EGF: Epidermal growth factor: FBS: Fetal bovine serum; FGF: Fibroblast growth factor; GPCR: G-protein coupled receptor; HE: Hematoxylin and eosin; HGF: Hepatocyte growth factor; Ibsp: Bone sialoprotein; IGF: Insulin-like growth factor; MSC: Mesenchymal stem
} 
cell; PBS: Phosphate-buffered saline; PDGF: Platelet-derived growth factor; PI3K: Phosphoinositide 3-kinase; TGF- $\beta$ : Transforming growth factor beta

\section{Acknowledgements}

The authors thank P. Barenblit, P. Fontova, and J. Moreno for their technical assistance.

\section{Funding}

This work was supported by grants from the MEC (BFU2011-24254 and BFU 2014-56313) and Fundació La Marató de TV3.

\section{Availability of data and materials}

All data generated or analyzed for this study are included in this published article.

\section{Authors' contributions}

RA-M and FVP conceived and designed the experiments. RA-M and APA performed the experiments. RA-M and FVP analyzed the data. RAM and FV wrote the paper. All authors read and approved the final manuscript.

\section{Ethics approval}

All animal procedures were performed in accordance with protocols approved by the Ethics Committee for Animal Experimentation of the University of Barcelona and by the Generalitat of Catalunya.

\section{Competing interests}

The authors declare that they have no competing interests.

\section{Publisher's Note}

Springer Nature remains neutral with regard to jurisdictional claims in published maps and institutional affiliations.

\section{Author details}

'Departament de Ciències Fisiològiques, Universitat de Barcelona, IDIBELL, L'Hospitalet de Llobregat, Barcelona, Spain. 'Division of Endocrinology, Mayo Clinic College of Medicine, Rochester, MN, USA.

Received: 3 July 2017 Revised: 18 October 2017 Accepted: 26 October 2017 Published online: 16 November 2017

\section{References}

1. Reddi AH. Morphogenetic messages are in the extracellular matrix: biotechnology from bench to bedside. Biochem Soc Trans. 2000;28(4):345-9.

2. Reddi AH. Morphogenesis and tissue engineering of bone and cartilage: inductive signals, stem cells, and biomimetic biomaterials. Tissue Eng. 2000:6(4):351-9.

3. Zipfel GJ, Guiot BH, Fessler RG. Bone grafting. Neurosurg Focus. 2003;14(2):e8.

4. Albrektsson T, Johansson C. Osteoinduction, osteoconduction and osseointegration. Eur Spine J. 2001;10 Suppl 2:S96-101.

5. Yamaguchi T, et al. Mouse osteoblastic cell line (MC3T3-E1) expresses extracellular calcium $\left(\mathrm{Ca}_{2}+0\right)$-sensing receptor and its agonists stimulate chemotaxis and proliferation of MC3T3-E1 cells. J Bone Miner Res. 1998;13(10):1530-8.

6. Gonzalez-Vazquez A, Planell JA, Engel E. Extracellular calcium and CaSR drive osteoinduction in mesenchymal stromal cells. Acta Biomater. 2014;10(6):2824-33.

7. Tang $Y$, et al. TGF-beta1-induced migration of bone mesenchymal stem cells couples bone resorption with formation. Nat Med. 2009;15(7):757-65.

8. Gamell C, et al. The p38/MK2/Hsp25 pathway is required for BMP-2-induced cell migration. PLoS One. 2011:6(1):e16477.

9. Fiedler J, et al. BMP-2, BMP-4, and PDGF-bb stimulate chemotactic migration of primary human mesenchymal progenitor cells. J Cell Biochem. 2002:87(3):305-12

10. Pietrzak WS, Ronk R. Calcium sulfate bone void filler: a review and a look ahead. J Craniofac Surg. 2000;11(4):327-33. discussion 334.

11. Strocchi $R$, et al. Bone regeneration with calcium sulfate: evidence for increased angiogenesis in rabbits. J Oral Implantol. 2002;28(6):273-8.

12. Kutkut A, Andreana S. Medical-grade calcium sulfate hemihydrate in clinical implant dentistry: a review. J Long Term Eff Med Implants. 2010;20(4):295-301.

13. Cho BC, et al. Clinical application of injectable calcium sulfate on early bony consolidation in distraction osteogenesis for the treatment of craniofacial microsomia. J Craniofac Surg. 2002;13(3):465-75. discussion 475-7.
14. Lazarou SA, Contodimos GB, Gkegkes ID. Correction of alveolar cleft with calcium-based bone substitutes. J Craniofac Surg. 2011;22(3):854-7.

15. Pecora $G_{\text {, et }}$ al. The use of calcium sulphate in the surgical treatment of a 'through and through' periradicular lesion. Int Endod J. 2001:34(3):189-97.

16. Kelly CM, et al. The use of a surgical grade calcium sulfate as a bone graft substitute: results of a multicenter trial. Clin Orthop Relat Res. 2001;382:42-50

17. Kelly CM, Wilkins RM. Treatment of benign bone lesions with an injectable calcium sulfate-based bone graft substitute. Orthopedics. 2004;27(1 Suppl):s131-5.

18. Tay BK, Patel W, Bradford DS. Calcium sulfate- and calcium phosphate-based bone substitutes. Mimicry of the mineral phase of bone. Orthop Clin North Am. 1999:30(4):615-23.

19. Barrere F, van Blitterswijk CA, de Groot K. Bone regeneration: molecular and cellular interactions with calcium phosphate ceramics. Int J Nanomed. 2006;1(3):317-32.

20. Thomas MV, Puleo DA, Al-Sabbagh M. Calcium sulfate: a review. J Long Term Eff Med Implants. 2005;15(6):599-607.

21. Walsh WR, et al. Response of a calcium sulfate bone graft substitute in a confined cancellous defect. Clin Orthop Relat Res. 2003;406:228-36.

22. Gazzerro E, Canalis E. Bone morphogenetic proteins and their antagonists. Rev Endocr Metab Disord. 2006;7(1-2):51-65.

23. Ghosh-Choudhury N, et al. Phosphatidylinositol 3-kinase regulates bone morphogenetic protein-2 (BMP-2)-induced myocyte enhancer factor 2A-dependent transcription of BMP-2 gene in cardiomyocyte precursor cells. J Biol Chem. 2003;278(24):21998-2005.

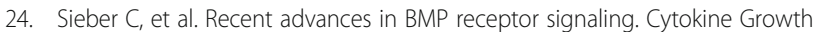
Factor Rev. 2009:20(5-6):343-55.

25. Gamez B, et al. Class I PI-3-kinase signaling is critical for bone formation through regulation of SMAD1 activity in osteoblasts. J Bone Miner Res. 2016;31(8):1617-30.

26. Ulsamer A, et al. BMP-2 induces Osterix expression through up-regulation of Dlx5 and its phosphorylation by p38. J Biol Chem. 2008;283(7):3816-26.

27. Ortuno MJ, et al. p38 regulates expression of osteoblast-specific genes by phosphorylation of osterix. J Biol Chem. 2010;285(42):31985-94.

28. Aquino-Martinez $\mathrm{R}$, et al. Mesenchymal stem cells within gelatin/CaSO4 scaffolds treated ex vivo with low doses of BMP-2 and Wnt3a increase bone regeneration. Tissue Eng A. 2016;22(1-2):41-52.

29. Choi $Y$, et al. Sinus augmentation using absorbable collagen sponge loaded with Escherichia coli-expressed recombinant human bone morphogenetic protein 2 in a standardized rabbit sinus model: a radiographic and histologic analysis. Clin Oral Implants Res. 2012;23(6):682-9.

30. Hong JY, et al. A high concentration of recombinant human bone morphogenetic protein-2 induces low-efficacy bone regeneration in sinus augmentation: a histomorphometric analysis in rabbits. Clin Oral Implants Res. 2016;27(12):e199-205.

31. Soleimani M, Nadri S. A protocol for isolation and culture of mesenchymal stem cells from mouse bone marrow. Nat Protoc. 2009;4(1):102-6.

32. Gamell C, et al. BMP2 induction of actin cytoskeleton reorganization and cell migration requires Pl3-kinase and Cdc42 activity. J Cell Sci. 2008:121(Pt 23):3960-70.

33. Wiggins H, Rappoport J. An agarose spot assay for chemotactic invasion Biotechniques. 2010:48(2):121-4.

34. Vinader $V$, et al. An agarose spot chemotaxis assay for chemokine receptor antagonists. J Pharmacol Toxicol Methods. 2011;64(3):213-6.

35. Ahmed $\mathrm{M}$, et al. Agarose spot as a comparative method for in situ analysis of simultaneous chemotactic responses to multiple chemokines. Sci Rep. 2017:7(1):1075.

36. Sawyer AA, et al. The stimulation of healing within a rat calvarial defect by $\mathrm{MPCL}-\mathrm{TCP} /$ collagen scaffolds loaded with rhBMP-2. Biomaterials. 2009:30(13):2479-88

37. Crane $J$, Cao X. Bone marrow mesenchymal stem cells and TGF-beta signaling in bone remodeling. J Clin Invest. 2014;124(2):466-72.

38. Teitelbaum SL. Stem cells and osteoporosis therapy. Cell Stem Cell. 2010;7(5):553-4.

39. Ma S, et al. Effects of dissolved calcium and phosphorous on osteoblast responses. J Oral Implantol. 2005;31(2):61-7.

40. Landesman $\mathrm{R}$, Reddi $\mathrm{AH}$. Chemotaxis of muscle-derived mesenchymal cells to bone-inductive proteins of rat. Calcif Tissue Int. 1986;39(4):259-62.

41. Ripamonti U. Biomimetism, biomimetic matrices and the induction of bone formation. J Cell Mol Med. 2009;13(9B):2953-72. 
42. Ripamonti U. Soluble and insoluble signals sculpt osteogenesis in angiogenesis. World J Biol Chem. 2010;1(5):109-32.

43. Olszak IT, et al. Extracellular calcium elicits a chemokinetic response from monocytes in vitro and in vivo. J Clin Invest. 2000;105(9):1299-305.

44. Robinson $D$, et al. Inflammatory reactions associated with a calcium sulfate bone substitute. Ann Transplant. 1999:4(3-4):91-7.

45. An S, et al. Short-term effects of calcium ions on the apoptosis and onset of mineralization of human dental pulp cells in vitro and in vivo. Int J Mol Med. 2015;36(1):215-21.

46. Nakashima $\mathrm{K}$, et al. The novel zinc finger-containing transcription factor osterix is required for osteoblast differentiation and bone formation. Cell. 2002;108(1):17-29.

47. Ducy P, et al. Osf2/Cbfa1: a transcriptional activator of osteoblast differentiation. Cell. 1997;89(5):747-54.

48. Lazary A, et al. Effect of gypsum on proliferation and differentiation of MC3T3-E1 mouse osteoblastic cells. Biomaterials. 2007;28(3):393-9.

49. Spinella-Jaegle $\mathrm{S}$, et al. Opposite effects of bone morphogenetic protein-2 and transforming growth factor-beta1 on osteoblast differentiation. Bone. 2001;29(4):323-30.

50. Standal T, et al. HGF inhibits BMP-induced osteoblastogenesis: possible implications for the bone disease of multiple myeloma. Blood. 2007:109(7):3024-30.

51. Kretzschmar M, Doody J, Massague J. Opposing BMP and EGF signalling pathways converge on the TGF-beta family mediator Smad1. Nature. 1997;389(6651):618-22.

52. Barradas AM, et al. Molecular mechanisms of biomaterial-driven osteogenic differentiation in human mesenchymal stromal cells. Integr Biol (Camb). 2013;5(7):920-31.

53. Tharmalingam S, Hampson DR. The calcium-sensing receptor and integrins in cellular differentiation and migration. Front Physiol. 2016;7:190.

54. Derynck R, Zhang YE. Smad-dependent and Smad-independent pathways in TGF-beta family signalling. Nature. 2003;425(6958):577-84.

55. Zhang W, et al. Calcium ion-induced formation of beta-sheet/-turn structure leading to alteration of osteogenic activity of bone morphogenetic protein-2. Sci Rep. 2015;5:12694

56. Aquino-Martinez R, et al. Extracellular calcium promotes bone formation from bone marrow mesenchymal stem cells by amplifying the effects of BMP-2 on SMAD signalling. PLoS One. 2017;12(5):e0178158.

57. Zhang $W$, et al. Strontium attenuates rhBMP-2-induced osteogenic differentiation via formation of Sr-rhBMP-2 complex and suppression of Smad-dependent signaling pathway. Acta Biomater. 2016;33:290-300.

58. Danciu TE, et al. Calcium regulates the PI3K-Akt pathway in stretched osteoblasts. FEBS Lett. 2003;536(1-3):193-7.

59. Dvorak MM, et al. Physiological changes in extracellular calcium concentration directly control osteoblast function in the absence of calciotropic hormones. Proc Natl Acad Sci U S A. 2004;101(14):5140-5.

60. Boudot $C$, et al. Implication of the calcium sensing receptor and the Phosphoinositide 3-kinase/Akt pathway in the extracellular calcium-mediated migration of RAW 264.7 osteoclast precursor cells. Bone. 2010;46(5):1416-23.

61. Suire $\mathrm{S}$, et al. Gbetagammas and the Ras binding domain of p110gamma are both important regulators of $\mathrm{PI}(3)$ Kgamma signalling in neutrophils. Nat Cell Biol. 2006;8(11):1303-9.

62. Jean S, Kiger AA. Classes of phosphoinositide 3-kinases at a glance. J Cell Sci. 2014;127(Pt 5):923-8.

63. Ballou LM, et al. Galphaq binds to p110alpha/p85alpha phosphoinositide 3-kinase and displaces Ras. Biochem J. 2006;394(Pt 3):557-62.

64. Vanhaesebroeck B, et al. The emerging mechanisms of isoform-specific PI3K signalling. Nat Rev Mol Cell Biol. 2010;11(5):329-41.

65. Taboubi S, et al. G alpha(q/11)-coupled P2Y2 nucleotide receptor inhibits human keratinocyte spreading and migration. FASEB J. 2007;21(14):4047-58.

66. Ichida $\mathrm{M}$, et al. Changes in cell migration of mesenchymal cells during osteogenic differentiation. FEBS Lett. 2011;585(24):4018-24.

\section{Submit your next manuscript to BioMed Central and we will help you at every step:}

- We accept pre-submission inquiries

- Our selector tool helps you to find the most relevant journal

- We provide round the clock customer support

- Convenient online submission

- Thorough peer review

- Inclusion in PubMed and all major indexing services

- Maximum visibility for your research

Submit your manuscript at www.biomedcentral.com/submit
Biomed Central 